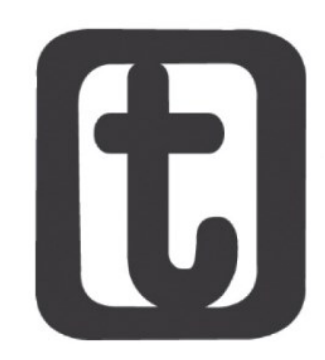

\title{
REFLEXÕES SOBRE O COTIDIANO E A ÉTICA PROFISSIONAL NO SERVIÇO SOCIAL
}

\author{
Reflections on daily life and professional ethics in social work
}

\begin{abstract}
Alberta Emília Dolores de Goes*
\section{RESUMO}

O presente artigo tem como objetivo problematizar e refletir o cotidiano a partir da atuação profissional em uma perspectiva ética no serviço social. Para o seu desenvolvimento, nos embasamos na literatura, principalmente, nos autores: José Paulo Neto, Myrian V. Baptista, Maria Lucia Barroco, Agnes Heller, dentre outros. Em uma conjuntura de barbárie social como a atual, o cotidiano além de trivial e rotineiro, deve ser visto como um espaço de reflexão e de oportunidades para o desenvolvimento de ações, estudos e pesquisas comprometidas com os usuários. Assim, assumir uma postura crítica frente a realidade social, que se materialize a partir de ações alinhadas com o Código de Ética profissional e o nosso projeto ético-político é ao mesmo tempo nosso desafio e meta.
\end{abstract}

\section{PALAVRAS-CHAVE}

Cotidiano. Atuação profissional. Ética e serviço social.

\section{ABSTRACT}

This article aims to problematize and reflect the daily life from the professional performance in an ethical perspective in the social service. For its development, we rely on the literature, mainly the authors: José Paulo Neto, Myrian V. Baptista, Maria Lucia Barroco, Agnes Heller, among others. In a conjuncture of social barbarism such as the current one, daily life, besides being trivial and routine, must be seen as a space for reflection and opportunities for the development of actions, studies and research committed to users. Thus, taking a critical stance on social reality, which materializes from actions aligned with the Code of Professional Ethics and our ethical-political project is both our challenge

\section{KEYWORDS}

Daily life. Professional work. Ethics and social work.

\footnotetext{
* Assistente Social. Mestre em Serviço Social. Doutoranda em Serviço Social pela Pontifícia Universidade Católica. Docente na Graduação do curso de Serviço Social da Universidade Santo Amaro de 2008 a 2018. Docente em Pós-graduação como professora convidada (Faculdade Paulista de Serviço Social - FAPSS). Assistente Social Judiciária do Tribunal de Justiça de São Paulo (TJSP, São Paulo, Brasil). Praça da Sé, s/nº, Cep. 01018-010. São Paulo. ORC ID: <https://orcid.org/0000-0003-0040-3400 >.E-mail: <goesalberta@gmail.com >.
}

DOI 10.22422/temporalis.2018v18n36p14-27 
O cotidiano é que nos conduziu à busca de aprofundamento em estudos e pesquisas, a partir da atuação profissional como assistente social na área judiciária, junto à infância e à juventude.

Neste clima institucional permeado pela formalidade, hierarquia, burocracia e agilidade onde direitos e justiça são alcançados, ou não, por intermédio de provas - o fazer, a atuação e o cotidiano são traduzidos, geralmente, por letras e palavras escritas que, por vezes, possuem maior importância do que os próprios sujeitos envolvidos nas ações judiciais.

Este cotidiano que, está emaranhado, geralmente, em uma atividade rotineira e familiarizada - com a demanda imposta pelas medidas de proteção à infância e à juventude - é difícil, tenso e envolto em uma complexidade que coloca em xeque, por vezes, as nossas capacidades profissionais.

O dia a dia imerso em uma atividade profissional que tem como foco situações de exploração, de violência, falta de oportunidades, violações de direitos, entre outros - que demandam respostas e avaliações que marcam, por vezes, destinos - é um espaço que impõe o constante investimento profissional em estudos, pesquisas e aprimoramento para evitar a homogeneização e o automatismo de intervenções e ações. Requisita ainda, a reflexão, a crítica e o posicionamento ético e político permanente. Nesse cotidiano há ainda, armadilhas e percalços que, podem nos conduzir a pontos cegos.

Nesse contexto - e em tantos outros espaços sociocupacionais de atuação do serviço social - a nossa atuação profissional pode se traduzir de forma fatalista - em que a sua condução é imersa na perspectiva de que não há o que fazer, já que a realidade está dada e é imexível - como também, pode se transformar em um arsenal de constatações em que situações de barbárie passam a ser vistas de forma banal, usual e recorrente, sem a apreensão da devida gravidade ali colocada.

Guerra (2014) ao discutir a instrumentalidade faz um importante alerta aos profissionais acerca da necessidade de refletirmos sobre a prática profissional, que pode se apresentar de forma fragmentada, repetitiva, automática e homogeneizada,

\footnotetext{
Nosso campo de percepção do cotidiano, pela via da razão instrumental, é o da mera repetição, da rotina, limitado ao âmbito das experiências imediatas, da empiria, do factual, dos imediatismos, do caos, do acaso, do fortuito. Assim, quando a ela recorremos, a sensação é a de que fazemos tudo o que podemos. Em decorrência de captarmos o cotidiano desta maneira, não nos perguntamos qual é o limite do possível, até onde o sujeito pode 'esticar' este limite que, aparentemente, se fecha em si mesmo. Assim, no cotidiano vemos limites, mas não possibilidades. Ora, é o próprio cotidiano, como espaço onde se manifestam as contradições, como espaço onde operam sínteses de múltiplas determinações, que nos permite análises mais concretas e complexas sobre o exercício profissional. Enquanto lamentamos as limitações não temos a percepção das possibilidades (GUERRA, 2014, p. 33-34).
}

Assim, é preciso ter em conta que no cotidiano, além de adversidades, há também possibilidades, sendo um espaço de criatividade, de resistência e de construção de perspectivas. 
Nesse sentido, encontramos na investigação, nos estudos e na pesquisa possibilidades de enfrentamento e de construção de novos conhecimentos para a atuação profissional cotidiana.

\section{Conforme Baptista (2006),}

[...] o que particulariza a investigação dos profissionais que atuam nas relações sociais é o fato de terem em seu horizonte um tipo determinado de intervenção: a intervenção profissional. Esses profissionais se detêm diante das mesmas questões que os outros pesquisadores, porém sua preocupação principal é a incidência sobre a prática que decorrerá do conhecimento produzido. É no movimento da ação que vão sendo elaboradas as pesquisas que irão construir novos conhecimentos. Para eles, o saber critico aponta para o fazer crítico. $O$ sentido de sua reflexão é o da realização de uma crítica de superação dos conhecimentos, já existentes, tendo como intencionalidade a sua apropriação em termos de prática, e o da construção de conhecimentos que apontem novos caminhos para a reflexão teórica e ofereçam novas condições de intervenção profissional [...] (BAPTISTA, 2006, p. 29).

E, ainda de acordo com a autora,

Desse modo, o que vai determinar o desempenho do profissional, em primeira instância, é o controle que ele (profissional) tenha sobre as variáveis da objetividade posta pela sociedade: a cotidianidade da prática: que revela presenças e ausências, aponta problemas imediatos, desvela/oculta uma questão central, o que se explica pelo fato de essa cotidianidade ser historicamente determinada. Nesse sentido, o conhecimento dela é apenas um ponto de partida para uma ação consequente, na qual o profissional, por aproximações sucessivas, vai desvelando sua objetividade, caminhando do particular, para o universal, do campo das micro atuações para o das relações sociais mais amplas, para retornar ao particular, às ações localizadas, em outro nível de reflexão. [...] Nesse sentido, parte-se do particular para o universal, para que se possa ter uma leitura e uma intervenção mais adequadas e consequentes sobre o particular. Isso significa que, para que haja uma ação efetiva sobre uma situação, é preciso conhece-la como uma totalidade que tem diferentes dimensões e se relaciona com totalidades maiores (BAPTISTA, 2006, p. 32).

Nessa direção, refletir sobre o cotidiano da atuação profissional é o desafio na tentativa de compreender o que fazer, como fazer, por que fazer, para quem, a quem defender, dentre outras tantas questões, diante da complexidade e da realidade social que se apresenta.

Acerca da atuação profissional cotidiana no serviço social, a autora Diniz (2010) apresenta reflexão que se mostra oportuna,

Diante das mudanças profundas que abrangem todas as esferas da vida social, principalmente nas duas últimas décadas, coloca-se, por exemplo, a questão: de que modo o Serviço Social vem se legitimando como prática institucionalizada na sociedade, frente às necessidades sociais derivadas das contradições das relações sociais? Ou, do ponto de vista da capacitação profissional, como dar conta das questões mais gerais e teóricas, que não estão postas imediatamente na diversidade dos fatos sociais, objetivados numa prática cotidiana? E, com a intenção de traçar novos recortes teóricos e empíricos, dimensionados na função social da pesquisa, quais mecanismos de investigação da realidade são utilizados 
pelo Serviço Social, e qual é a legitimidade de seus produtos para a construção de um perfil profissional que venha atender às demandas atuais da sociedade, coerente com uma prática crítica? (DINIZ, 2010, p. 41-42).

Desse modo, dependendo do campo de atuação em que estamos inseridos se faz necessário à nossa formação para atuação nessa área especifica. Nessa direção, para o trabalho, por exemplo, na área judiciária é fundamental buscar espaços de formação permanente, considerando a complexidade e diversidade de situações a que os profissionais estão submetidos.

De acordo com Agnes Heller não há homem sem cotidiano,

A vida cotidiana é a vida do homem inteiro, ou seja, o homem participa na vida cotidiana com todas as suas capacidades intelectuais, suas habilidades manipulativas, seus sentimentos, paixões, ideias, ideologias [...] o homem da cotidianidade é atuante e fruidor, ativo e receptivo, mas não tem nem tempo nem possibilidade de se absorver inteiramente em nenhum desses aspectos, por isso não pode aguçá-los em toda sua intensidade (HELLER, 2001, p. 30).

No trabalho, construímos e reconstruímos a nossa identidade. Nele, lidamos com situações da vida humana e ao mesmo tempo com nossas próprias vidas. No dia a dia sofremos impactos do processo de trabalho que, nos atingem, nas diferentes esferas da vida.

Nessa direção, somos constantemente invadidos pelo cotidiano que rouba nosso tempo, pela heterogeneidade de atividades a serem desenvolvidas, e frequentemente repetimos não ter tempo para o aprofundamento e para o estudo, já que sempre estamos ocupados.

A vida cotidiana é, em grande medida heterogênea, e isso sob vários aspectos, sobretudo no que se refere ao conteúd o e a significação ou importância de nossos tipos de atividade. São partes orgânicas da vida cotidiana: a organização do trabalho e da vida privada, os lazeres e o descanso, a atividade social sistematizada, o intercambio e a purificação (HELLER, 2001, p. 32).

Desse modo, o desafio é pensar o cotidiano, não só como o passar dos dias, mas, como um espaço contraditório e complexo onde se constrói e reconstrói o trabalho.

Refletir sobre o cotidiano, não significa aqui pensar sobre o conceito exclusivamente, mas, analisar as suas intrínsecas relações societárias, que têm dinâmicas que incidem sobre o trabalho e o trabalhador, ou seja, também sobre nós mesmos.

As questões que se colocam para o profissional se direcionam, principalmente, a refletir sobre como a nossa atuação pode se desenvolver na perspectiva de um maior alcance de justiça social possível. Assim, é preciso refletir, sobre como podemos contribuir para uma cultura que se fundamente nessa direção.

Heller ao discutir o cotidiano, aponta três perspectivas sobre a cotidianidade para o alcance da esfera do humano-genérico,

O meio para essa superação dialética (Aufhebung) parcial ou total da particularidade, para sua decolagem da cotidianidade e sua elevação ao humanogenérico, é a homogeneização. Sabemos que a vida cotidiana é heterogênea, que 
solicita todas as nossas capacidades em várias direções, mas nenhuma capacidade com intensidade especial. Na expressão de Georg Lukács: é o 'homem inteiro' [ganze Mensch] quem intervém na cotidianidade. O que significa homogeneização? Significa, por um lado, que concentramos toda nossa atenção sobre uma única questão e 'suspendemos' qualquer outra atividade durante a execução da anterior tarefa, e, por outro lado, que empregamos nossa inteira individualidade humana na resolução dessa tarefa. Utilizamos outra expressão de Lukács: transformamo-nos assim em um homem inteiramente [Menschen ganz]. [...] Apenas quando esses três fatores se verificam conjuntamente é que podemos falar de uma homogeneização que se eleva totalmente acima da cotidianidade para penetrar na esfera do humano-genérico. (HELLER, 2001, p. 43-44)

O grande desafio colocado por Heller pode ser interpretado a partir da reflexão de como nós, enquanto profissionais e, em um contexto de infinitas demandas, conseguimos estar inteiro e inteiramente em cada uma das atividades que desenvolvemos.

Nesse sentido, como conseguimos focar ou homogeneizar as nossas energias sobre aquilo que estamos desenvolvendo, se há uma heterogeneidade de demandas que nos solicitam?

Nessa direção, é preciso estar inteiro do ponto de vista dos nossos pensamentos, das nossas reflexões, das nossas perspectivas de análise sobre o que está acontecendo e inteiramente em nossas ações e articulações.

Como conseguimos manter o foco sobre determinado sujeito, respeitando a sua singularidade, com ações e atividades direcionadas a este e suas necessidades, sem nos dispersar nas inúmeras demandas a nós destinadas em aspectos relacionados à vida pessoal, profissional, cumprimento de metas, produtividade, demandas virtuais, dentre outros?

De acordo com Faleiros (2014) o cotidiano nos incita a um compromisso ético político, com vistas a buscar romper com o processo de alienação comum ao contexto capitalista em que se insere as nossas ações profissionais,

O compromisso ético do cotidiano é uma dimensão crucial da ação profissional para superar as alienações de si mesmo em relação ao contexto capitalístico das instituições. As instituições sociais nas quais assistentes sociais, psicólogos, pedagogos e outros profissionais exercem suas atividades, postulam como valores a produtividade, a exequibilidade, o controle pelo alto, a eficiência na redução de tempo e custo, usando-se a informática para a concentração dos dados nas mãos de gestores. Em muitas instituições o uso do computador está controlado pela mesma, com espionagem do seu uso por parte dos gestores em nome da chamada segurança institucional. O institucional predomina sobre a dinâmica da relação em favor do cliente, pois o medo da demissão ronda profissionais e funcionários (FALEIROS, 2014, p. 719).

À medida que atuamos profissionalmente devemos manter-nos sempre atentos para a leitura da realidade, e nesse caso, do cotidiano. Nesse sentido, destaca-se a importância enquanto profissional de se reconhecer naquilo que se faz e, de não se anular enquanto sujeito das ações desenvolvidas nas lutas que travamos cotidianamente. 
Não podemos ser a representação da política, e sim o sujeito que materializa e executa a política e dessa forma, precisamos manter a nossa identidade como sujeitos políticos. Entretanto, é preciso pensar então, que os espaços de alienação são mais fáceis de serem vividos do que aqueles em que se aprofundam à análise crítica. A repetição ao invés da construção, muitas vezes se torna o caminho mais fácil.

\begin{abstract}
A vida cotidiana, de todas as esferas da realidade, é aquela que mais se presta a alienação. Por causa da coexistência 'muda', em-si, de particularidade e genericidade, a atividade cotidiana pode ser atividade humano-genérica não consciente, embora suas motivações sejam, como normalmente ocorre efêmeras e particulares. Na cotidianidade, parece 'natural' a desagregação, a separação de ser e essência. Na coexistência e sucessão heterogêneas das atividades cotidianas, não há porque revelar-se nenhuma individualidade unitária; o homem devorado por e em seus 'papéis' pode orientar-se na cotidianidade através do simples cumprimento adequado desses 'papéis'. A assimilação espontânea das normas consuetudinárias dominantes pode converter-se por si mesma em conformismo, na medida em que aquele que as assimila é um indivíduo sem "núcleo"; e a particularidade que aspira a uma 'vida boa', sem conflitos reforça ainda mais esse conformismo com a sua fé (HELLER, 2001, p. 57).
\end{abstract}

Daí, decorre a necessidade de estar atento para a presença do pensamento ultrageneralizante, que segundo Heller - não traz a possibilidade de refletir as particularidades, como por exemplo, a despolitização da questão social - apenas generaliza. É preciso problematizar e ter o cuidado de não assumir práticas profissionais imediatistas e superficiais, que se tornem verdadeiras armadilhas para o trabalho cotidiano.

Assim, se faz presente uma questão: como construir práticas que possam superar as expressões de pensamentos conservadores?

Os estudos de Barroco (2010) apontam que os riscos oriundos do cotidiano, merecem destaque, já que avalia que é o espaço privilegiado para a reprodução da alienação, em que pode ocorrer a falta de crítica, a repetitividade de valores, a rigidez de preceitos e de comportamentos, a partir de um pensamento repetitivo e ultrageneralizador, em decorrência de moralismo e preconceito.

No cotidiano da vida pessoal e profissional, temos que dar conta da nossa reprodução física e singular com o trabalho, os estudos, os afetos, as relações familiares, entre outros. Esse contexto, propõem a realização de inúmeras tarefas e de relações muito heterogêneas; e nessa dinâmica da cotidianidade com intensidade, não conseguimos, por vezes, nos colocarmos por inteiro em nenhuma das atividades desenvolvidas, considerando a diversidade de ações a serem realizadas.

Desse modo, podemos ficar imersos nessa dinâmica, acríticos, fazendo atividades repetitivas, com o automatismo de hábitos, que fatalmente poderá culminar na alienação, na reprodução da ideologia dominante e, consequentemente na reprodução de uma moral conservadora.

A moral pode se apresentar, por intermédio de estereótipos, com a reprodução de atitudes moralistas, com julgamentos de valor e generalizações. Assim, é necessário compreender 
que o moralismo é uma reprodução alienada e, que pode se reproduzir de modo discriminatório e preconceituoso.

Ao longo do processo, podemos mudar ou não uma ideia pré-concebida, mas podemos ser preconceituosos se não refletirmos, mantendo uma atitude típica do senso comum. Assim, no trabalho profissional a reflexão é fundamental, já que toda ação terá consequências para o ‘outro' (usuário, família, criança e adolescente, entre outros).

No cotidiano profissional é necessário fazer reflexões não preconceituosas, analisando a situação de modo a refletir, avaliar cuidadosamente, discutir com outras pessoas, buscar conhecer e apreender mais profundamente o outro com recursos teóricos e práticos sobre a sua situação concreta.

Netto (2012) em seus estudos sobre o cotidiano se baseia, principalmente, nos autores Agnes Heller e Henri Lefebvre. Para tanto, aborda a experiência do cotidiano não apenas como algo repetitivo, desestimulante, rotineiro e trivial, aponta que é a partir dele que podem emergir grandes possibilidades de criação e transformação da realidade. Aborda a necessidade de que os profissionais consigam desenvolver formas de suspensão do cotidiano como modo de romper com o pragmatismo, o automatismo e a alienação.

Essa passagem ocorre, como diz Agnes Heller, quando se rompe com a cotidianidade; quando um projeto, uma obra ou um ideal convoca a inteireza de nossas forças e então suprime a heterogeneidade. Há nesse momento uma objetivação. A homogeneização é a mediação necessária para suspender a cotidianidade. Este processo de homogeneização só ocorre quando o indivíduo concentra toda a sua energia e a utiliza numa atividade humana genérica que escolhe consciente e autonomamente.

A intensidade de uma grande paixão, um grande amor, o trabalho livre e prazeroso, uma intensa motivação do homem pelo humano genérico resultam na suspensão do cotidiano (NETTO, 2012, p. 27).

Ainda segundo Netto (2012) a partir dos estudos de Heller (1972),

[...] há quatro formas de suspensão da vida cotidiana, de passagem meramente singular do humano genérico. São elas: o trabalho, a arte, a ciência e a moral.

Esta suspensão da vida cotidiana não é fuga: é um circuito porque se sai dela e se retorna a ela de forma modificada. À medida que estas suspensões se tornam frequentes, a reapropriação do ser genérico é mais profunda e a percepção do cotidiano fica mais enriquecida.

Nesta suspensão, a singularidade se conhece como participe da universalidade (totalidade). $\mathrm{O}$ indivíduo sente, mesmo que temporariamente, a plenitude existencial, a plenitude de comunhão consigo próprio, com os homens e com o mundo. Esta suspensão é temporária, mas a apreensão de plenitude obtida permite ganhos de consciência e possibilidade de transformação do cotidiano singular e coletivo (HELLER, 1972, p. 27).

Nessa direção, de acordo com Barroco (2012) a suspensão da cotidianidade pode trazer ainda o enriquecimento, a consciência e a motivação por exigências, em nosso caso éticas, que passam a ser incorporadas ao fazer profissional. 
Assim, compreendo que os estudos e pesquisas no e sobre o cotidiano podem se processar como uma forma de suspensão do cotidiano, no sentido de darmos outro tratamento para o arroz-com-feijão do dia a dia, oportunizando novas reflexões, possibilidades e construções para o trabalho profissional e para a intervenção profissional na realidade estudada.

\section{O Cotidiano, o ethos burguês e a prática profissional}

A partir deste cotidiano, a prática profissional do assistente social deve considerar a reflexão contínua e a não generalização das situações apresentadas, no sentido de investir em uma postura profissional que garanta a ética e a construção de mediações que se traduzam na oferta de possibilidades para o alcance de 'reais' garantias de direitos.

Assim, é preciso a reflexão acerca do significado amplo do trabalho social, nessa direção, em que o Serviço Social enquanto profissão pode contribuir para este projeto, para o cotidiano, para os nossos estudos e para mudanças sociais?

Entendo que a direção social do nosso fazer profissional se processe a partir das contradições que o 'real' nos coloca e que, deve se desenvolver por um pensamento político, que se distancie do conservadorismo profissional, do pragmatismo, do individualismo, da especificidade e da particularidade das situações, a partir de uma reflexão que seja ampliada.

Assim, é preciso construirmos um pensamento reflexivo, teórico e crítico para nos voltarmos a prática em sua singularidade, e não nos basearmos apenas na especificidade das situações, afinal, em nosso caso especifico, os problemas não estão em indivíduos, famílias e territórios isolados de um sistema social.

Em um mundo neoliberal, para a apreensão da realidade social - principalmente, a partir das últimas décadas - há a exigência da análise da reestruturação produtiva, das transformações sociais, de um movimento direcionado a aumentar taxas de lucros, dentre outros.

Nesse contexto, na prática profissional, como somos coagidos a agir dentro do imediato e com respostas pragmáticas?

O cotidiano não nos deixa refletir, quer respostas rápidas e resolutivas, tudo se resume a gestão e a agilidade, ou seja, ao tempo de gestão, que nos leva para o maniqueísmo ${ }^{1}$ que não nos permite refletir.

Nesse contexto, o movimento do real, se direciona para análises que possui dois aspectos centrais: a cooptação dos trabalhadores (construção de pactos sociais) onde trabalhadores se tornam consumidores, respondendo as demandas do mercado. E, por

\footnotetext{
${ }^{1}$ De forma sintética, a partir da tentativa de perceber a realidade social de forma simplista com a dualidade entre o 'bom e o mau'.
} 
outro lado, é esse o trabalhador que faz parte da 'classe perigosa'. Portanto, há um controle policialesco, com formas autoritárias de atuar sobre as suas vidas.

Assim, temos um movimento - bem presente na atual conjuntura - que é alimentado pelas grandes mídias, que transforma o trabalhador em consumidor passivo, ou pior, ainda, em trabalhador-perigoso.

Nessa direção, o discurso da mídia é moralizante e tem como perspectiva o movimento de valorizar o ethos burguês - o consumo - de responder as demandas do mercado, de fortalecer a descrença política nas formas democráticas construídas historicamente. Elementos de um cenário em que as contradições não estão aparentes, já que apresentam imagens homogeneizadas e que pretendem transformar tudo em um pensamento único.

Nesse sentido, para tentarmos um melhor entendimento sobre a questão dos valores na sociedade capitalista, nos apoiamos em Barroco (2010) que ressalta,

[...] na sociedade capitalista os valores éticos, estéticos, tendem a se expressar como valores de posse, de consumo produzindo sentimentos, comportamentos e representações individualistas, negadoras de alteridade e da sociabilidade livre. Por exemplo, o amor pode ser vivido como coisa, isto é, como algo que tem valor de troca, de consumo, de posse. A liberdade, que existe em função da capacidade deliberadora e socializadora do homem, pode se transformar objetivamente, em seu oposto; pode ser vivenciada como algo que impede a sociabilidade e autonomia. É o que ocorre quando os indivíduos vivem exclusivamente voltados ao 'eu', tratando o outro como um limite à sua liberdade. Principalmente, as normas e deveres morais passam a configurar-se como exigências externas aos indivíduos; exigências que não lhes dizem respeito, mas a que devem 'obedecer'; a moral se transforma num conjunto de obrigações formais, marcadas por um significado negativo, repressivo (BARROCO, 2010, p. 35-36).

De acordo com a autora, essa forma de organização cria uma moral dominante que, se coloca como universalizante com normas e valores que correspondem ao ethos dominante que não é só uma forma subjetiva de dominação, mas a reprodução do modo de produção econômica de toda a sociedade.

Assim, o ethos dominante na sociedade capitalista é aquele que, divulga como felicidade maior, o individualismo, sendo essa forma de pensar fundamental para a reprodução do capitalismo que supõem a posse de bens descartáveis a cada momento. No individualismo, cada um possui a sua casa, o seu celular, enfim, o seu e o meu é preponderante.

O ethos dominante propõe ainda, a manutenção do clientelismo, do coronelismo, do favoritismo, da barbárie, entre outros. O direito ao 'meu', ou seja, ao individualismo e a fragilidade ou inexistência do pensamento coletivo traz o desafio da reflexão cotidiana.

A ideia é o individualismo, ou seja, a salvação individual, o sucesso e os valores da sociedade burguesa são bem trabalhados junto a classe trabalhadora. A ideologia propõem um pensamento único - assim, a mídia, a classe dominante e a classe trabalhadora, o assumem como seu. 
Neste contexto, ao fazermos um paralelo com o trabalho desenvolvido concretamente com as famílias em situação de vulnerabilidade social que adentram, em nosso caso, o sistema judiciário, facilmente o posicionamento do profissional pode vir a ser de julgamento, do uso do preconceito, do moralismo², do poder institucional, da intimidação, dentre outros.

Assim, é necessário agir eticamente, com a capacidade da consciência, discernindo entre valores, a partir de escolhas, criando alternativas, projetando e considerando as finalidades a serem alcançadas. A ação prática para defender certos valores é teleológica, isto é, uma ação ética.

A reflexão ética supõe a suspensão da cotidianeidade; não tem por objetivo responder às suas necessidades imediatas, mas sistematizar a crítica da vida cotidiana, pressuposto para uma organização da mesma para além das necessidades voltadas exclusivamente ao "eu", ampliando as possibilidades de os indivíduos se realizarem como individualidades livres e conscientes (BARROCO, 2010, p. 55

Ainda segundo Barroco,

A ética realiza sua natureza de atividade propiciadora de uma relação consciente com o humano-genérico quando consegue apreender criticamente os fundamentos dos conflitos morais e desvelar o sentido e determinações de suas formas alienadas; quando apreende a relação entre a singularidade e a universalidade dos atos ético-morais; quando responde aos conflitos sociais resgatando os valores genéricos; quando amplia a capacidade de escolha consciente; sobretudo, quando indaga radicalmente sobre as possibilidades de realização da liberdade, seu principal fundamento (BARROCO, 2010, p. 56).

Ainda segundo a autora, as práticas baseadas em uma cultura conservadora, possuem uma relação direta com a precarização da formação profissional, da falta de preparo técnico e teórico, da fragilização de uma consciência crítica, de processos de despolitização, de incorporação de valores e ideologias conservadoras, individualistas, irracionalistas, da absorção da rotina burocrática das instituições e submissão às suas normas e aos seus valores, entre outros, o que vem sendo agravado na conjuntura atual (BARROCO, 2012, p. 75).

A permanente reflexão sobre o cotidiano, aliada à formação continuada, à busca de embasamento teórico, à compreensão do projeto ético-político-ideológico do Serviço Social, ao entendimento de sua processualidade, a compreensão da história da própria profissão, suas demandas sociais, sua relação teoria e prática, e seu posicionamento ético político é o desafio constante.

Assim, neste contexto e a partir da reflexão sobre o cotidiano e da sociabilidade capitalista, é necessário ter o cuidado para não reduzir o escopo do nosso trabalho, tentando entender as questões apresentadas - por exemplo pelas famílias - como se fossem algo exclusivo

\footnotetext{
2 $E$ uma forma de alienação moral, pois implica na negação da moral como uma forma de objetivação da consciência critica, das escolhas livres, de construção da particularidade. Ao mesmo tempo, a intolerância remete ao dogmatismo, também negador da liberdade (BARROCO, 2010, p. 48).
} 
e/ou vivenciados/criados por elas mesmas, ou seja, não podemos incorrer na ausência de análise, de reflexão, de planejamento, entre outros.

\section{Considerações Finais}

A partir de um olhar de retrovisor é possível dizer que o serviço social - enquanto profissão, em sua história - se tornou laico, se profissionalizou, se institucionalizou, se instrumentalizou, se reconceituou, se transformou e se estabeleceu na divisão sócio técnica do trabalho.

Surgiu das cidades, da divisão social, do assalariamento, do êxodo rural e das profundas mudanças na estrutura social que originou o seu objeto: a questão social. Questão social que norteou as relações cada vez mais antagônicas entre o capital e o trabalho, em uma economia que não produzia equilíbrio e tão pouco assegurava as garantias sociais ao trabalhador.

Descobriu que a sociedade não é harmônica, que existe luta de classes, que a desigualdade social é uma realidade, que não há neutralidade, que há contradição, que como profissionais precisamos ter uma posição crítica frente à realidade social.

E que, na atualidade e no cotidiano, a posição profissional da categoria é a defesa intransigente da classe trabalhadora, a luta pela justiça social, pela cidadania e pelos direitos.

A partir desse panorama acerca da profissão e de sua direção social, no cotidiano profissional reforçamos a necessidade de conhecer e reconhecer a história e da reflexão permanente, principalmente na atual conjuntura que conta com poucos avanços e muitos retrocessos na perspectiva dos direitos sociais.

Assim, desde a década de 1990 temos um cenário de (des) proteção social a partir da lógica neoliberal que vem se traduzindo na redução do Estado, com a diminuição dos níveis de emprego, dos sistemas protetivos, do acesso aos direitos assistenciais, com a concentração da riqueza, o aumento da pobreza e da indigência, entre outros.

Na atualidade há também o aumento do número de indivíduos, famílias e comunidades que vivem em condições precárias por causa da grande desigualdade social. Há a redução dos direitos básicos (civis, políticos e sociais) e da qualidade de vida. Temos ainda, o desemprego estrutural, a flexibilização da mão de obra, as terceirizações, a instabilidade do trabalho, a perda dos direitos trabalhistas, o aumento da pobreza, o empobrecimento da classe média, a privatização dos serviços sociais, dentre outros.

Nesse contexto, segundo lamamoto (2008), a lógica neoliberal conduz à banalização do humano, à descartabilidade e a indiferença.

Traz ainda "[...] a subordinação da sociabilidade humana às coisas - ao capital-dinheiro e à capital mercadoria -, retrata, na contemporaneidade, um desenvolvimento econômico que se traduz como barbárie social" (IAMAMOTO, 2008, p. 125). 
Nessa conjuntura, de acordo com Potyara Pereira-Pereira (2004), “[...] desde a crise econômica mundial dos anos 1970, a família vem sendo redescoberta como um importante agente privado de proteção social" (PEREIRA-PEREIRA, 2004, p. 26).

Temos o familismo, caracterizado por Marta Campos (2016) como a exigência de um esforço interno da parte dos familiares adultos - em especial da mulher - mãe desproporcional, em face a suas possibilidades - na prestação de cuidados até então incluídos nos sistemas de proteção social publica, e decidida como obrigatória no âmbito das definições desses mesmos sistemas (CAMPOS, 2016, p. 202).

Ainda nesta perspectiva, de acordo com lamamoto (2006),

a atual desregulamentação das políticas públicas e dos direitos sociais desloca a atenção à pobreza para a iniciativa privada ou individual, impulsionada por motivações solidárias e benemerentes, submetidas ao 'arbítrio do indivíduo isolado', e não à responsabilidade pública do Estado (IAMAMOTO, 2006, p.3).

Esse tipo de ação pode ser caracterizado como uma volta ao passado, uma vez que estabelece um retorno as formas de proteção social articuladas ao mundo privado e a esfera primária das relações.

Conforme Mesquita et al. (2010), é nesse quadro, que ganham destaque as famílias pobres e suas questões. Essas famílias aparecem necessariamente como um problema social, principalmente diante da ausência de serviços públicos, como: creches, escolas, saúde, saneamento básico, habitação entre outros.

Nessa conjuntura, impera ainda o ethos dominante que propõem o individualismo, o favoritismo, a barbárie, entre outros. A salvação individual em detrimento do coletivo, a ideia central é o individualismo, o sucesso - valores da sociedade burguesa que são muito bem trabalhados junto a classe trabalhadora a partir de uma ideologia que propõe um pensamento único. Assim, a mídia, a classe dominante e a classe trabalhadora o assumem como seu.

\section{E o Serviço Social?}

Os assistentes sociais são convocados a intervir nas relações cotidianas visando a ampliação e a consolidação da cidadania na garantia dos direitos civis, políticos e sociais aos segmentos menos favorecidos e mais vulnerabilizados.

Assim, problematizar as expressões da questão social e a sua relação com os sujeitos e as famílias com quem atuamos no cotidiano da prática profissional é fundamental.

Nesta conjuntura, e com toda a força ideológica dominante há riscos para o trabalho profissional que se apresenta no cotidiano. Rotineiro, repetitivo e constante, pode trazer armadilhas baseadas em uma postura acrítica, com automatismo de hábitos, com a repetitividade de valores, rigidez de preceitos e de comportamentos. Pode ainda, reproduzir a ideologia dominante, a moral conservadora, atuando o profissional pelo senso comum, com moralismo e generalizações e não pela ética profissional. 
Barroco aponta que essa postura tem uma relação direta com o processo de formação profissional,

[...] as práticas baseadas em uma cultura conservadora, possuem uma relação direta com a precarização da formação profissional, com a falta de preparo técnico e teórico, com a fragilização de uma consciência crítica, com processos de despolitização, de incorporação de valores e ideologias conservadoras, individualistas, irracionalistas, da absorção da rotina burocrática das instituições e submissão às suas normas e aos seus valores, entre outros, 0 que vem sendo agravado na conjuntura atual (BARROCO, 2012, p. 75)

E, para finalizarmos, deixamos algumas reflexões oriundas do cotidiano profissional:

Será que no cotidiano, percebemos o desemprego estrutural, a precarização no mercado de trabalho, a competição, a redução do associativismo, o individualismo, o imediatismo, o consumismo e que, todas essas mudanças impactam a vida das pessoas e das famílias as quais atendemos?

Será que compreendemos que as determinações sociais vão incidir no modo de vida da família que estou acompanhando? Ou, apenas julgamos, culpabilizamos e responsabilizamos as famílias?

Em que o Serviço Social enquanto profissão pode contribuir para uma outra sociabilidade?

Entendemos que a direção social do nosso fazer profissional se processa a partir das contradições que o real nos coloca, e deve se desenvolver por um pensamento político, que se distancie do conservadorismo profissional, do pragmatismo, do individualismo, da especificidade e da particularidade das situações, e que possa ser refletido de forma ampliada?

Por fim, entendemos que é preciso construir um pensamento reflexivo, teórico e crítico para nos voltarmos a prática em sua singularidade - e não nos basearmos apenas na especificidade das situações - já que, em nosso caso especifico, os problemas não estão em famílias isoladas de um sistema social?

Assim, neste contexto e a partir da reflexão sobre o cotidiano e da sociabilidade capitalista, precisamos refletir para não reduzir o escopo do nosso trabalho, tentando entender as questões apresentadas - por exemplo pelas famílias - como se fossem algo exclusivo e/ou vivenciados/criados por elas mesmas, ou seja, não podemos incorrer na ausência de análise, de reflexão, de planejamento, entre outros

Acreditamos que a permanente reflexão sobre o cotidiano, aliada à formação, à busca de articulação entre a relação teoria/prática em uma práxis transformadora, o direcionamento do projeto ético-político do Serviço Social, deve ser a nossa busca e desafio constante.

\section{Referências}

BAPTISTA, M. V. A Investigação em Serviço Social. São Paulo: Veras, 2006. 
BARROCO, M. L. Ética e Serviço Social, fundamentos ontológicos. 8. ed. São Paulo: Cortez, 2010.

BARROCO, M. L. Ética Fundamentos sócio-históricos. 3. ed. São Paulo: Cortez, 2010.

BARROCO, M. L.; TERRA, S. H. Código de Ética do Assistente Social Comentado. São Paulo: Cortez, 2012.

CAMPOS, M. S. O casamento da política social com a família: feliz ou infeliz? In: MIOTO, R. C. T., CAMPOS, M. S. e CARLOTO, C. M. (Orgs.). Familismo: direitos e cidadania Contradições da Política Social. São Paulo: Cortez, 2016. p. 21-43.

DINIZ, T.M.R.G. O estudo de caso. In: PESQUISA qualitativa: um instigante desafio. São Paulo: Veras, 2010.

FALEIROS, V. P. O Serviço Social no Cotidiano: fios e desafios. Serviço Social e Sociedade, São Paulo: Cortez, n. 120, p. 706-722, out./dez. 2014.

FREITAS, R. de C. S; MESQUITA, A. de A. As novas expressões da "questão social" e as famílias brasileiras: reflexões para o serviço social. In: ENCONTRO NACIONAL DE PESQUISADORES EM SERVIÇO SOCIAL, 15., 2016, Ribeirão Preto. Anais... Ribeirão Preto, 2016.

GUERRA, Y. A Instrumentalidade do Serviço Social. 10. ed. São Paulo: Cortez, 2014.

HELLER, A. O cotidiano e a história. São Paulo: Paz e Terra, 2001.

IAMAMOTO, M. V. As dimensões ético-políticas e teórico-metodológicas no Serviço Social. In: MOTA, Ana Elizabete et al. (Orgs.). Serviço social e saúde: formação e trabalho profissional. São Paulo: ABEPSS, Organização Pan Americana de Saúde; OMS Brasil, 2006.

IAMAMOTO, M. V. Serviço Social em tempo de capital fetiche: capital financeiro, trabalho e questão social. 3. ed. São Paulo: Cortez, 2008.

NETTO, J. P. Cinco Notas a propósito da "Questão Social”. Temporalis, Brasília (DF): ABEPSS, Ano 2, n. 3, jan./jun. 2001.

NETTO, J. P. A construção do projeto ético-político do serviço social. In: MOTA, Ana Elizabete et al. (Orgs.). Serviço social e saúde: formação e trabalho profissional. São Paulo: ABEPSS, Organização Pan Americana de Saúde; OMS Brasil, 2006.

NETTO, J. P. ; BRANT DE CARVALHO M. C. Cotidiano: conhecimento e critica. 10. ed. São Paulo: Cortez, 2012.

PEREIRA-PEREIRA, P. A. Mudanças estruturais, política social e papel da família: crítica ao pluralismo de bem-estar, In: POLÍTICA Social, Família e Juventude: uma questão de direitos. São Paulo: Cortez, 2004. 